International Journal of Science and Education, 4(1), 16-27

Uluslararası Bilim ve Eğitim Dergisi, 4(1), 16-27

DOI: 10.47477/ubed.783928

Makale Türü: Derleme

Başvuru Tarihi: 01.10.2020

Yayına Kabul Tarihi: 23.01.2021

\title{
Fark et, anda kal; namıdiğer Mindfulness: Farkandalık uygulamalarının dünü, bugünü ve kültüre duyarlılığı
}

Öz

\author{
Bilge UZUN ${ }^{*}$, Tennur KRAL ${ }^{2}$
}

Bu derleme çalışmasında, son yıllarda tüm dünyada olduğu gibi ülkemizde de tanınır bir yaklaşım olan mindfulness kavram ve uygulamalarına ilişkin alan yazın taraması ve yaklaşımın kültüre duyarlığının incelenmesi amaçlanmıştır. Buna göre, fark' andalık olarak kullanılan kavramın tanımı ve felsefesinin paylaşılmasının ardından yaklaşımın diğer kuramlarla ortaklığı özetlenmiştir. Buna göre Freud ile başlayan süreç Gestalt yaklaşımı ve Varoluşçu yaklaşımla mindfulness yaklaşımına zemin oluşturmuştur. Bilişsel davranışçı yaklaşımın üzerine oturtulan düşüncelerin yönetilmesi, tinsel bakış açısıyla ayrımsama olarak sunulmuştur. Hümanistik yaklaşımın öncüsü Carl Rogers'ın büyük etkileri görülmektedir. Günümüzde çağdaş yaklaşımlar kapsamında oluşturulan mindfulness temelli terapiler de açıklanmıştır. Çalışmada fark'andalık uygulamalarının psikolojik danışmada ve eğitimde, önemine de değinilmiştir. Uluslararası çalışmaların yanı sıra ulusal çalışmaların da özetlendiği çalışma farkandalığın günümüzde bulunduğu yeri de içermektedir.

Anahtar Kelimeler: Fark'andalık, çağdaş yaklaşımlar, kültüre duyarlılık

\section{Notice and stay in the moment; a.k.a Mindfulness: Past, present and cultural sensitivity of mindfulness practices}

\begin{abstract}
In this review study, it is aimed to review the literature on the concept and practices of mindfulness, which is a well-known approach in our country as in the rest of the world, besides evaluating the cultural sensitivity. Accordingly, after discussing the definition and philosophy of the concept used as fark' andalık in Turkish, the commonality within other theories is summarized. In this respect, process of understanding human behavior started with Freudian Psychoanalytic approach laid the groundwork for the mindfulness within the Gestalt and the Existential theory. Managing thoughts based on cognitive behavioral approach is presented as defusion from a spiritual point of view. Carl Rogers, the pioneer of the humanistic approach, has great effects on mindfulness. In recent, mindfulness-based therapies developed within the scope of contemporary approaches are also explained. In the study, the importance of difference practices using in education and psychological counseling was also mentioned. The current review study, summarizing national and international research results, also includes the current place of the mindfulness today.
\end{abstract}

Key Words: mindfulness, current approaches, culture sensitive.

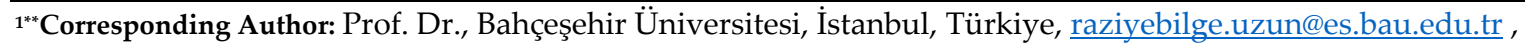
ORCID: 0000-0001-6107-7384:

2Uzm. Psk. Danışman, Bahçeşehir Üniversitesi, İstanbul, Türkiye, tennur.kral@gmail.com, ORCID: 0000-0002-4056-1094
} 


\section{Giriş}

Budist psikoloji dili olan Pali dilindeki Smrit kökeninden gelen Sati kelimesinin çevirisi olan mindfulness sözcüğü 2500 yıl öncesine kadar dayanmaktadır. Hem Doğu hem de Batı kültürünü çevreleyen bu kavram antik yıllardan itibaren gelişmeye başlamıştır (Alidina, 2010; Mace, 2008; Germer, 2005). Kavram ilk olarak Amerikalı tıp doktoru Jon Kabatt-Zinn tarafından, İngilizce zihin anlamına gelen 'mind' ve dolu anlamına gelen 'full' kelimelerinin birleşimiyle oluşmuş dolu zihin anlamındaki 'mind full' kavramına karşıllık olarak türetilmiştir. Buna göre, sıfat olan mindfull kavramının isim hali olan, mindfullness kelimesindeki ' 1 ' sesinin düşmesiyle türetilen mindfulness kelimesinin İngilizce karşılığı da yoktur. Kabat Zinn (2003) mindfulness kavramını zihnin bilinçli ve yargısız bir biçimde içinde bulunulan an'a getirilmesi olarak tanımlanmıştır.

Mindfulness kavramına ilişkin tanımlamaların içinde bulunulan an'ı deneyimleme, yargıların farkında olma, kabul etme, içsel gözlemleme gibi ortak bileşenleri olduğu görülmektedir (Çatak ve Ögel, 2010). Terimin kavramsal içeriğinin zengin olması, farklı dillere çevirisini de güçleştirmektedir. Bu nedenle Türkçe alan yazında aynı kavramı ifade eden farklı terimlere rastlamak mümkündür. Buna göre, Çatak ve Ögel (2010) kavramı 'farkındalık' olarak kullanırken, Özyeşil (2011) 'bilinçli farkındalık' olarak belirtmektedir. Karacaoğlan ve Hisli Şahin (2016) mindfulness kavramının Türkçe karşılığını 'bilgece farkındalık' olarak kullanmıştır. Uzun (2020a, 2020b) ise 'mindfulness' kavramının Türkçe karşılığını, zihnin bilinçli olarak içinde bulunulan an'a çekilmesi anlamını içerdiğinden hareketle 'fark etmek' ve 'anda kalmak' kelimelerinin birleşimi olan 'fark'andalık' terimini önermektedir. Bu doğrultuda bu çalışmada kavramın zengin içeriğini daha iyi yansıttığı düşünülen 'fark'andalık' terimi kullanılmaktadır.

Dikkati maksatlı bir biçimde ve yargısızca içinde bulunulan an'a vermek (Kabat-Zinn, 2003) olarak tanımlanan fark'andalık, kişinin bilinçlilik halini şimdiki gerçeklikte tutma halidir (Hanh, 1987). Buna göre fark'andalık anının bazı ortak özellikleri vardır (Germer, 2005). Fark'andalık, an'a odaklı, kavramsal ve yargılayıcı olmayan, sözcüklerden bağımsız, özgürleştirici ve keşfe dayalı, maksatlı ve kişinin gözlemini gerektiren bir süreçtir. Açık ve sevgi dolu bir tavırla içinde bulunulan an'da neler olduğuna dikkati yöneltmektir (Snel, 2016).

Fark'andalık (mindfulness) durumunun karşıtı zihnin geçmiş ya da gelecek düşünce ve hayaller arasında gezinmesi (mindlessness), halk dilinde 'dalma' olarak nitelendirilebilir. Tadı alınmadan atıştırılan yiyecekler, dikkatsizce kırılan nesneler, anda olmadan yapılan etkinlikler, tanıştıktan hemen sonra unutulan isimler, fark edilmeyen bedensel rahatsizlıklar fark'andasızlık (mindlessness) olarak örneklendirilebilir (Brown ve Ryan, 2003). Fark'andalık düzeyi düşük olan bireyler, iletişimde oldukları kişilerin davranışlarına dikkat edemedikleri gibi dürtüsel ve otomatik davranma eğilimine sahiptirler (Özyeşil, 2011). Fark'andalık, kişinin yaşadığı durumu iyi-kötü, olumluolumsuz, güzel-çirkin gibi etiketleyici olmadan ve kategorileştirmeden, yargılamadan kabul eden bir ruh haline ulaşmaktır (Terzi ve Tekinalp, 2013). Fark'andasızlı̆ı̆n aksine, fark'andalık kaygı, endişe, üzüntü gibi yaşantısal anılara odaklanmak yerine onları serbest bırakmayı içerir (Çatak ve Ögel, 2010). Kaçınma ve aşırı yüzleşmenin tam tersi olan fark'andalık duygusal olarak açıklık, kabullenici bir yaklaşım, duygu durumunu düzenleyebilme ve bilişsel esneklik halidir (Hayes ve Feldman, 2004). Fark'andalık geçmiş ve gelecekleriyle, kaygı ve beklentileriyle, pişmanlıklarıyla uğraşan bireylerin an'a odaklanmasını sağlayarak uyanık bir zihne geçmelerine yardımcı olur (Gilbert, 2005). Fark'andalık becerilerinin kazanımının sonrasında birey, duygu ve düşüncelerin denizdeki dalgalar gibi gelip geçici olduğu farkındalığına ulaşabilir (Baer, 2003). 


\section{Fark'andalık Becerileri}

Fark'andalık temelde beş beceriye odaklanmaktadır. Bunlar; an'da olma, yargıların farkında olma, mesafe koyma, serbest bırakma ve kabul becerileridir. Fark'andalık alıştırmalarının tümü bireyi dikkatini bulunduğu an'a çekmesini amaçlar (Surrey, 2005). Duncan (2003), bireyin an'da olma becerisini beş duyu organını da aktif bir şekilde kullanarak gelecek ya da geçmişi düşünmeden dikkatini o andaki duyumlarına yöneltmesi olarak açıklar. Geçmişe dair duyulan pişmanlık ve kontrol etme isteği ve geleceğe dair olan beklentiler neşe, huzur ve mutluluk için bir araç değildir (Ginnivan, 2016). Geçmişin belirsizliği ve geleceğin beklentilerinden medet ummak yerine kişi kendi dünyasında o an olup bitene odaklanmalıdır (Duncan, 2003). Yargiların farkında olma becerisi, bireyin hem kendisinde hem de çevresinde gerçekleşenlere eleştiri, kategorileştirme, etiketleme ya da yargılamada bulunmadan bakabilme becerisidir (Roemer ve Orsillo, 2008). Bu bakış açısı kişiye kötü sonuçları ve olumlu-olumsuz duyguları kabul etme becerisi kazandırmakla birlikte tüm deneyimlerini de olduğu gibi kabul etmesini sağlar (Fiorillo ve Fruzetti, 2015). Birey deneyimi ile ilgili doğru-yanlış, iyi-kötü, güzel-çirkin gibi etiketlemelerle değerlendirmek yerine onları olduğu haliyle kabul eder. Suçlama, eleştiri, inkâr gibi ifadelerle kavga etmeyi durdurarak merhamet gösterir (Alidina, 2015). Alan yazın incelendiğinde gözlemlenen fark'andalık becerilerinde, yargısız kalmak terimi yerini yargıları farkında olmak olarak değişmeye başladığı gözlemlenmiştir (Yıldızhan, 2019). Fark'andalık yoluyla kazanılan becerilerden biri olan mesafe koyma bireyin duygu ve düşüncelerinin farkında olması anlamına gelmektedir (Demir, 2014). Birey duygu, düşünce ve kendisi arasında bir mesafe olduğunun bilincinde olmalıdır. Düşüncelerin ve duyguların sadece bir düşünce ve duygu olduğunu, kişinin kendisinin bir parçası olmadığını ifade eder (Germer, 2005). Fark'andalık becerilerinden serbest bırakma becerisi, rahatsızlık veren içsel deneyimlere tepki vermek yerine yanıt vererek bu deneyimleri serbest bırakabilmesini sağlamaktır (Ögel, 2012). Kişinin olayları fark ettiği anda hoşa giden ya da hoşa gitmeyen haliyle kabul etme arzusuna dayanır (Germer, 2005). Kabul etme bireyin yaşantısındaki deneyimleri iyi-kötü, doğruyanlış olarak algılamamasını içermektedir (Fiorillo ve Fruzetti, 2015). Kabul etme becerisi, yargılamamanın bir uzantısıdır. Bireyde rahatsızlık hissi uyandıran duygu ve düşünceleri bastırmak ya da onlardan kaçınmak yerine onlara yaklaşarak kabul etmesini sağlamaktır (Demir, 2014).

\section{Fark'andalık Felsefesi}

Budizm felsefi temellerine dayandırılan (Baer ve diğerleri, 2006) fark'andalık, içinde bulunulan an'da oluşan deneyime ve deneyimin birey tarafından an-be-an fark edilmesine vurgu yapar. Buna göre her deneyim önemlidir. Yaşam, varoluşla temas kurma ya da var olanla bağlanma deneyimidir (Janning, 2017).

Budizm, M.Ö. 4. Yüzyıldan 6. yüzyıl ortalarına kadar kuzey Hindistan'da yaşamış ruhani bir lider olan Siddharta Gautama Buddha'nın öğretilerinden doğan bir felsefedir. (Kumar, 2002). Budist öğretisi yaşamın, 'kalıcı olmama', 'acı çekme' ve 'içgörü' olmak üzere üç özelliği olduğunu belirtir. Buna göre yaşam deneyimlerinin kalıcı olmadığını, an-be-an değişebildiği bilmek, kişinin kendi 1stıraplarından arınmasının yanı sıra benlik ve deneyimlerin kabulünü de getirir (Kumar, 2002).

Ruhani lider Buda'nın ölümünden sonra, Budizm'in iki mezhepi olan Theravada ve Mahayana Budizmi Hindistan ve Asya'nın üst bölgelerine yayılmıştır. Theravada Budistleri Buda'nın öğretilerini katı bir biçimde korurken, Mahayana Budistleri öğretilerde daha liberal bir yorum izler. Daha sonra liberal Budizm mezhebi Moğolistan, Tibet, Çin, Japonya, Kore, Vietnam, Nepal, Sri Lanka, Tayland ve Burma gibi farklı ülkelere yayılmıştır. 8. Yüzyıla gelindiğinde, Budizm'in farklı alt mezhepleri de geliştirilmiştir. Bunlardan biri, Mahayana Budizm'inin bir alt dalı olan 'Zen Budizmi' dir ve 9. yüzyılda Çin Budizm'i tarafından Japonya'ya tanıtılmıştır. Hint ve Orta Asya Budizm'inin Çin kültürüyle karşılaşması sonucu yeni bir yorum katılarak Zen'in ortaya çıkmasını sağlamıştır. 'Zen' kelimesi, Çince 'Ch'an'ın Japonca telaffuzu olup 'meditasyon' anlamına gelir. Zen Budizm, esas olarak bireysel 
meditasyon deneyimine vurgu yapar. Tarih boyunca Budizm'in etkileri Batı Dünyasına ulaşır. 19. yüzyılın ortalarından başlayarak, Japon Zen Budizm'i aracılığıyla Budist meditasyonu Amerika Birleşik Devletleri ve diğer Batı ülkelerine tanıtılmaya başlar. Zamanla, Zen Budizmi Amerika Birleşik Devletleri'nde (ABD), Zen Budizmi, Psikanaliz, Doğu ve Batı Psikoterapisi (Watts, 1961) ve Fark'andalığın gücü (Thera, 1972) olarak tanınmaya başlamıştır.

20. yüzyılın ortalarında Zen meditasyonu, zamanın tanınmış psikoterapistlerinin yazılarıyla ABD'de önem kazanmıştır. Örneğin, uygulamaların bilinç dışı duygu ve düşüncelerin fark edilmesini sağladığı düşünülmüştür. Bu doğrultuda meditasyonun şimdi ve burada, kendiliğindenlik/spontanite ve kabul üzerine yaptığı vurgu nedeniyle psikoterapiye uyumu fark edilmiştir (Watts, 1961). Bu dönemde ayrıca, büyüme ve değişim üzerinde önemli rol oynadığı düşünülen Zen Budizm'i, klinik psikoloji alanında varoluşçu ve hümanist yaklaşımı benimseyen terapistler tarafından benimsenmiştir (Kumar, 2002).

Günümüzde ruh sağlığı uzmanları, Budizm'in öğretileriyle psikoterapinin yöntemlerinin entegre edilmiş halini bireylerin sıkıntılarını azaltma ile deneysel uygulama ortamı yaratması bakımından kullanışlı bulmaktadır (Özyeşil, 2011). Birçok felsefi ve psikolojik gelenek gibi fark'andalık da insanın iyilik halini arttırmayı amaçlamaktadır. Budizm bakış açısıyla fark'andalık, evreni ve evrendeki konumumuzun durumunu fark ederek bilinçsizlik durumundan uyanıştır (Salmon, Santorelli, Sephton, ve Kabat-Zinn, 2009). Normal işleyişe ara vererek tüm korku, kayg1, hırs, rekabet, koşuşturma, umut gibi esarete mahkum olmayan sade bir yaşantıyı deneyimlemektir (Rinpoche, 2006). Williams ve Penman (2014), fark'andalık uygulamalarının bir inanç sistemi olmadığını, uygulama yapan bireylerin herhangi bir dinin üyesi olabildiği gibi, ateist ya da agonist olabileceğini de ifade etmektedir.

Fark'andalık her ne kadar Budizm kökenlerine dayanıyor olsa da uygulamaların Antik Yunan felsefesi, Varoluşçuluk akımı, Batı kültürünün Doğalcıllğıı, Amerikan kültürünün Hümanizmi gibi felsefelerle de ortak kavramları bulunduğu görülmektedir (Demir, 2014). Benzer inanç ve uygulamalara Mevlana Celaleddin Rumi'nin Mesnevilerinde bulunan deyişlerinde de rastlamak mümkündür (Uzun, 2019). Bu bağlamda fark'andalığın bir inanç, dini bir sembol ya da bir ibadet biçimi değil sağaltıcı bir teknik olduğu düşünülmektedir. Buna göre fark'andalık uygulamaları, dağılmış, parçalanmış olan insan zihninin dinginlik ve sükunete kavuşmasını hedeflemektedir (Rinpoche, 2006). Bu doğrultuda uygulamalar Batı dünyası tarafından bir kültür unsuru ve bir dini görevden ziyade, bireylerde var olan değerlerin birikimi olarak kabul edilerek (Kabat-Zinn, 2003) seküler bir bir yol gösterici yorumunu kazanmıştır (Uzun, 2020).

\section{Kuramsal Temellendirmede Fark'andalık}

Fark'andalık yaklaşımının yaşamı ele alışı, felsefesi, amacı ve kavramlarının, psikolojik danışma ve psikoterapi kuramlarıyla örtüştüğü anlaşılmaktadır. Geliştirilebilen bir yetenek olan fark'andalık, psikoloji bilimi içerisinde de kuramsal alanda ve uygulama alnında kendine yer bulmuştur (Germer, 2009). Örneğin, fark'andalık kavramının Psikanalitik kuramın 'ideal zihin' (ideal mind) kavramıla büyük oranda örtüştüğü görülmektedir. Benzer olarak Erich Fromm farkındalığı, Hint ve Çin kültürünün harmanlanması sonucu oluşan bir aydınlanma yolu olarak tanımlamıştır (Demir, 2014).

Latner (1992), Gestalt yaklaşımının en temel kavramının farkındalık olduğundan bahsetmiş ve kişinin büyüme ve gelişiminin ilk koşulunu farkındalık olarak açıklamıştır. Fark'andalık yaklaşımında görülen 'değişimin yaparak değil, olarak' gerçekleşmesiyle (Killingsworth ve Gilbert, 2010) benzerlik göstermektedir. Fark'andalık, kişinin duygu, düşünce ve davranışlarında dikkatini 'şimdi-veburada'ya davet etmesidir. Geçmişte yaşamaya sığınmak ya da henüz gelmemiş bir geleceği beklemek 
yerine kişi an'ı yaşayabilmelidir (Daş, 2012). Benzer olarak Geştalt terapilerinde de psikolojik danışman, bireyin anlattıklarını şimdiki zaman eki kullanarak tekrar anlatmasını, bu yöntemle danışanın yeni seçeneklerin farkına varmasını hedefler (Daş, 2012).

Yalom (2001), varoluşsal psikoterapinin dayandığı temel kavramları ölüm, anlam, yalıtılmışlık, özgürlük olarak belirtmiştir. İnsanoğlu doğasında kaçışı olmayan yaşlanma, hastalık, ölüm ve sevdiklerinin değişimi ya da ayrılması vardır. Bununla birlikte kişi, kendi yaşadıklarının sorumluluğunu alabilecek tek kişidir (Hanh, 1998). Budist felsefenin 'Beş Anımsama' olarak belirttiği ilkeler (çalma, canlıya zarar verme, sarhoş olma, istismar etme, yalan söyleme) ile dört temel öğretisi olan acıyı kabul etmek, acının sebebini araştırmak, acının son bulacağını ve sonlandırmaya giden yolu fark etmek öğretileri Varoluşsal ekolün kavram ve temellendirmesiyle de örtüşmektedir. Her iki görüşte de ölümden kaçış mümkün olmadığı için, yaşamın anlamlı kılınarak yaşanması esastır.

Fark'andalık yaklaşımında Hümanist yaklaşımın da etkileri görülmektedir. Buna göre, birey kendine özgüdür ve yaşamını anlamlı kılma sorumluluğu kendisine aittir. Hümanist hareketin önder temsilcilerinden olan Carl Rogers, bireyin duygu ve düşüncelerini yargısızca ve özgür bir biçimde keşfedebileceğini ifade etmektedir (Dryden ve Still, 2006).

Hem Bilişsel Davranış̧̧ı Terapi (BDT) yaklaşımın hem de fark'andalık yaklaşımının dünyaya bakış açısının temelinde düşünceler yatmaktadır. Bununla birlikte düşüncelerin nasıl ortaya çıtığı, bu düşüncenin sonucunda deneyimin ne olduğu, rahatsızlık veren düşüncelerle nasıl baş edileceği konusunda zihni eğitme bakış açısında da bir benzerlik söz konusudur (Gilbert, 2005). Fark'andalık temelde düşünceleri rasyonel-irrasyonel, olumlu-olumsuz gibi kategorileştirmeden olduğu gibi kabul etme ve geçip gitmelerini izleme temeline dayanmaktadır (Roemer ve Orsillo, 2008). Her iki görüşe göre de algı ve düşüncenin uyumsuz değişimi kökleşmiş bir öz yıkıma neden olabilmektedir (Miller, Fletcher ve Kabat-Zinn, 1995).

Fark'andalık temelli terapiler Bilişsel Davranışçı Terapilerin üçüncü dalgası olarak nitelendirilmektedir (Hayes, 2004). Buna göre, davranış̧̧ yaklaşımı içeren birinci dalga terapi uygulamaları koşullanmaların oluşma ve kırılma biçimine odaklanmıştır. İkinci dalga terapiler bilişsel davranışçı terapi ve akılcı duygusal terapi olarak adlandırılmış ve davranışın değişmesi için düşünceye odaklanmışır. Üçüncü dalga terapiler ise ilk iki modelin yetersiz kalması ve uzun vadede semptomların nüksetmesi nedeniyle oluşmuştur. Bireyin kendini kabul etmesini içeren fark'andalık ve kabul etme temalarına odaklanmıştır (Brown, Ryan ve Creswell, 2007). Bu terapilerin içinde yer alan Diyalektik Davranış̧̧ı Terapi (DDT), diyalektik felsefeye dayanan ve kabul üzerine şemalanan bir tekniktir. Kişinin kendisi hakkında karmaşıklığı, kişilerarası ilişkilerindeki karışıklığı, dürtüselliği ve duygu düzenleme problemlerine odaklanır (Linehan, 2015; Çakır \& Uzun, 2018). DDT problemi belirleyerek baş etme yöntemlerine odaklanır. Bireylerin yaşadığı kaygı ve acı gibi yoğun ve yorucu duygularla baş etmede etkili bir yöntem olduğu görülmektedir (Mckay, Wood ve Brantley, 2016). Diğer bir çağdaş yönelim olan Kabul ve Kararllık Terapisi'nin (KKT, Hayes, 2004a) amacı kaçınma davranışını azaltmak, bilişsel ve davranışsal esnekliği sağlayabilmek için beceri edinimini sağlamaktır (Killen, Fortmann ve Newman, 2008). Fark'andalık temelli KKT modelinde esneklik kavramı için 6 bileşen önemlidir. Bunlar, anda olmak (şimdi ve burada), ayrışma (düşünceleri izleme), kabul emek (açı olmak), bağlamsal benlik (salt farkındalık), değerler (birey için değerli ve önemli olanlar) ve değerlere yönelik eylemlerdir (gerekenin yapılması) (Hayes, Strosahl ve Wilson, 1999). KKT'nin temel hedefi rahatsızlığın azaltılması değil rahatsızlık veren belirtilerin bireyle ilişkisinin düzenlenerek an'a odaklı yaşamasını sağlamaktır (Harris, 2016). 


\section{Günümüzde Fark'andalık Uygulamaları}

Üçüncü dalga terapilerden olan Fark'andalık temelli terapiler, DDT ve KKT'nin yanı sıra Fark'andalık Temelli Stres Azaltma Programı (FTSA, Mindfulness Based Stress Reduction- MBSR), Fark'andalık Temelli Bilişsel Terapi (FTBT, Mindfulness Based Cognitive Therapy- MBCT) ve Öz Şefkatli Fark'andalık Terapisi (ÖŞFT, Mindfull Compassion Therapy) uygulamalarını içermektedir. FTSA programı, Massachusetts Üniversitesi Tıp Merkezinde tedavi alan hastaların kronik ağrılarını hafifletmek amacıyla 1990 yılında John Kabat-Zinn tarafından geliştirilmiştir. Hastalıkları iyileştirmede birincil tedavi yöntemi olmayan bu teknik, tıbbi tedavilere ek olarak, hastanın aktif katılımı ile uygulanır (Perry, 2017). En fazla 30 kişilik gruplarda her biri iki-iki buçuk saat süren 8 haftalık bir program olarak yapılandırılmaktadır. Zihinsel süreçlerin anlık deneyimini sistematikleştiren bu program nefes egzersizleri, beden tarama egzersizleri, günlük işlerinin rutinine dikkati vermeyi içermektedir (Dryden ve Still, 2006). FTSA programında, programa katılan olan bireyin yaşamında kontrol edemediği birçok şeyin olabileceği, bunları kabul ederek dünyayı algılama biçimini değiştirmesi hedeflenir (Perry, 2017). Programın en önemli sonuçlarından biri de duyum, duygu ve düşüncelerin denizdeki dalgalar gibi gelip geçici olduğunun fark edilmesidir (Baer, 2003). Williams, Teasdale ve Segal (2002) tarafından depresyon yaşayan bireylerin bir süre sonra aynı semptomları geliştirmesi üzerine bu yöntemi kullanmışlardır (Williams ve Penman, 2015). FTBT, FTSA yöntemleriyle Bilişsel Davranışçı terapinin yöntemlerinin birbirine entegre edilmesiyle oluşan bir sistemdir (Teasdela ve diğg., 2002). Ek olarak bilişsel davranış̧̧ı terapilerin terapötik ilişki yönüne önemli ölçüde katkı sağlamıştır (Broderic, 2005). Bilişsel terapi ilkelerini dikkat ve meditasyonla bütünleştiren bu teknikle depresyon tanısı alan kişilerle anlamlı sonuçlar elde edilmiştir (Shirish, Prakash ve Shivarama, 2018; MacKenzie, Abbott ve Kocovski, 2018). Son on beş yıl içerisinde yapılan çalışmalar ele alındı̆̆ında üç ya da daha fazla kez depresyonu deneyimleyen bireylerin FTBT uygulaması sonrasinda belirtilerin nüksetme oranının \% 50 oranında azaldığı görülmüştür (Orsillo, Roemer \& Holowka, 2005).

Öz Şefkatli Farkındalık Temelli Terapiler (ÖŞFT) pozitif psikolojinin iyilik halini arttırma amacını destekler. ÖŞFT, öz yargılamaya karşı öz sevecenlik, özdeşleşmeye karşı fark'andalık, izolasyona karşı ortak bilinç olarak hem olumlu hem olumsuz parçası olan üç faktörden oluşmaktadır (Neff, 2003b). Şefkat Odaklı Terapi, terapötik ortamda kendine bakım verme ve sıkıntıyı tölere etme gibi becerilerini arttırmak ve kendini yargılamadan sıcak duygular yaşayabilmesine katkı sağlamaktır (Gilbert, 2009).

\section{Psikolojik Danışma Sürecinde Fark'andalık}

Psikolojik danışman ve danışanın beraber yürüttüğü terapötik ortamın şimdi ve burada ilkesiyle şekillenmesi, dikkatin verileceği yönü ve empatiyi güçlendirir (Hick, 2008). Hanh (1987), fark'andalık sahibi bireyi, kendi bilincini şimdiki anda tutması olarak tanımlamaktadır. Bu bağlamda birbiri ardına gelen birçok olayın içinde algının iç dünyasında aslında neler olduğunun fark edilmesini engelleyen durumu ancak şimdiki an'ın içine dikkat verilerek görülebilir (Thera, 1973). Son yıllarda psikolojik danışmanlar fark'andalık uygulamalarının kendi kişisel gelişimlerinin yanı sıra, teröpatik ilişkilerini geliştirmeye yönelik olarak da kullanmaktadır. Uygulamaların, bireylerin ve içinde bulundukları durumların ihtiyacına uyacak şekilde biçimlendirilmesi kullanımın etkinliğini arttırmaktadır (Uzun, 2019; Pollak, Pedula \& Siegel, 2014).

Psikolojik danışmada fark'andalık uygulamaları çeşitli şekillerde görülür (Germer, 2013). Örneğin fark'andalık uygulamalarını düzenli olarak deneyimlendiğinde, danışanlarla kurulan ilişki doğal olarak farklılaşmaya başlamaktadır. Zihnin dikkat kapasitesi arttıkça bunu danışma odasında göstermek, zihni odaklayarak hem danışmanın kendine hem de danışana ait an-be-an ortaya çıkan düşüncelerin ve duyguların farkına varmak daha da kolaylaşmaktadır. Bu bağlamda uygulamaların duygu töleransı artışında etkili olduğu bilinmektedir (Fulton, 2013). 
Fark'andalık temelli çalışmalar psikolojik danışmada bireysel uygulamaların yanı sıra grupla psikolojik danışma ve psikoeğitim gruplarında da etkili biçimde kullanılmaktadır. Fikir alışverişine dayalı bu yöntemler bir rehberin yardımıyla öğrenmeye ve materyallerle zenginleştirilmeye uygun bir yapısı vardır. Program, danışanların ihtiyaçları doğrultusunda her bir oturum için belirli çerçeveler çizilerek ilerleyebilir (Mace, 2008).

\section{Eğitimde Fark'andalık Uygulamaları}

Son yıllarda fark'andalık becerilerinin eğitimde uygulandığı alanlar artmakta ve eğitim alanındaki bilimsel çalışmalara ağırlık verilmektedir. 2009 yılından günümüze eğitimde fark'andalık/bilinçli farkındalık/mindfulness başlığı sıklıkla araştırılmaktadır. Bu doğrultuda eğitimde fark'andalık uygulamaları üç aşamada ilerlemektedir. Çalışmaların ilk aşamasında, uygulayıcı öğretmenlerin hem kişisel hem de mesleki alanlarında fark'andalık uygulamaların benimsemeleri, ikinci aşamasında kendi kişisel fark'andalık sürecini tamamlamış olan öğretmenlerin fark'andalık becerilerini öğrencilerine öğretmeleri ve üçüncü aşamasında ise eğitim modelinin içeriğinde fark'andalık becerilerinin yerleştirilmesi bulunmaktadır (Meiklejohn, vd., 2012). Fark'andalık becerilerinin eğitim alanındaki etkileri incelenirken çoğunlukla psikolojik iyilik hali, duygu regülasyonu, dikkat becerilerinin artışı, empati ve öz şefkat gibi sosyal becerilerin gelişimi değişkenlerinin ele alındığı görülmektedir (bknz, Uzun \& Saraç, 2020; Yıldızhan, 2018; Kral, 2019; Yazğan, 2019).

Öğretmen ve okul liderlerinin eğitim anlayışı ve yaşam becerilerine katılan fark'andalık becerileri ile ilgili yapılan bazı araştırmaların sonuçlarına göre öğretmenlerin becerileri benimsemelerinin ve kişisel yaşamlarına dahil etmelerinin sonucu olarak öğrencilerin olumlu etkilendiği görülmüştür. Örneğin, Meiklejohn ve arkadaşları (2012) tarafından yürütülen çalışma bulguları, 14 hafta uygulanan FTSP'nın öğretmenler aracılığı ile öğrencilere uygulanmasının öğrencilerde dikkat becerilerinin güçlendiği, akademik zorluklarla daha kolay baş edebildiklerini ortaya koymuştur. Benzer olarak, okul öncesinde hizmet veren öğretmenlere uygulanan iletişim becerileri ve teknikler ile fark'andalık becerilerinden oluşan 8 haftalık programın, öğrencilerde etkili dinleme ve saygı düzeyinde artış oluştururken, olumsuz davranışların sergilenmesinde azalma olduğunu ortaya koymuştur (Singh, Lancioni, Winton, Karazsia ve Singh, 2013). Flook ve ark. (2010) tarafından, yaşları 7-9 arasında değişen çocuklarla yapılan grup çalışmasının ardından çocuklarda planlama, problem çözme, dürtü kontrolü ve zihinsel esneklik ile ilgili farka rastlanmış ve bu fark ebeveyn ve öğretmenler tarafından da sosyal hayatta gözlemlenmiştir.

FTSP'nın 8 hafta süren uygulamasının sonucunda katılımclardan alınan MR (Magnetic Resonance) sonuçlarına ve öntest-sontest puanlarına göre öğrenme ve duygu merkezi olan hipokampüs bölümündeki gri madde yoğunluğunda artma, duygusal merkez olan amigdala bölgesinde ise madde yoğunluğunda azalma görülmüştür (Hölzel ve ark., 2011). Dikkat ve konsantrasyon becerileri üzerinden de araştırılan fark'andalık programı deneysel bir düzenek kullanılarak 4 gün boyunca katılımclara sunulmuş ve programın sonunda katılımciların dikkat becerileri ve konsantrasyon düzeylerinde artış saptanmıştır (Zeidan ve ark., 2010). Benzer düşünceleri sürekli olarak geri getirme anlamına gelen ruminasyon ile fark'andalık arasındaki ilişkinin incelendiği bir araştırmanın sonucuna göre ise fark'andalık düzeyi yüksek olan bireylerin ruminasyon düzeylerinin düşük olduğu ortaya konulmuştur (Raes ve Williams, 2010). Okul öncesi düzeyinde uygulanan programın da çocuklarda dikkatli olma, sakin olma, öz denetimli davranma, kendini kabul ve sevme, başkalarına karşı ilgili ve yardımsever olma düzeylerini arttırdığı görülmektedir (Çollak, 2018). Fark'andalık Temelli Öfke Yönetim Psikoeğitimi programı (Yıldızhan, 2019) ve Fark'andalık temelli kaygı yönetimi (Kral, 2019) psikolojik danışma uygulamaları yoluyla öğretilen becerilerin öğrencilerin öfke ve kaygı gibi zor duyguları yönetme becerileri kazanmalarında etkili olduğu görülmüştür. 
Üniversite öğrencileriyle yapılan psikolojik iyilik hali ve fark'andalık düzeyi çalışmasının sonucunda katılımcıların fark'andalık düzeyi ile duygulanım düzensizliği, kaygı ve depresyon puanlarında negatif; yaşam doyumu, benlik saygısı, optimistlik düzeylerinde pozitif yönde ilişkili çıkmıştır (Brown ve Ryan, 2003). Cash ve Wittingham'ın (2010) araştırma sonucu da yine benzer bir veriyi ifade etmektedir. Fark'andalık, depresif ruh hali ve kaygı semptomlarının arasındaki ilişkiye bakıldığında fark'andalık puanı yüksek olan bireylerin depresif ruh hali ve kaygı puanlarının düşük olduğu gözlemlenmiştir. Algilanan stres düzeyi ve baş etme becerilerinin incelendiği başka bir araştırma bulgusu, fark'andalık düzeyi yüksek olan bireylerin mantıksal baş etme yöntemlerini kullanırken, fark'andalık düzeyi düşük olan bireylerin duygusal/kaçınmacı baş etme yöntemine daha sık başvurduğu görülmüştür (Palmer ve Rodger, 2009). Genel anksiyetesi yüksek olan üniversite öğrencileriyle üst bilişsel ve psikolojik süreçlerinin ele alındığı deneysel bir çalışma bulgularında ise tehlikenin kontrol edilemezliği, algılanan stres ve iyi oluş halinde anlamlı sonuçlar ile ilişkiyi yordadığı görülmüştür (Keçeli, 2017). Anksiyete şikayeti olan bireylerle yapılan çalışmada katılımcıların fark'andalık becerilerinin ve öz şefkat düzeylerinin düşük olduğu sonucuna ulaşılmıştır (Roemer ve ark., 2008).

\section{Kültüre Duyarlı Fark'andalık Uygulamaları}

Fark'andalık yaklaşımının temeli olarak bilinen Budizm bir din değil yaşam felsefesidir. Bununla birlikte, biri diğerinden farklı yaklaşımlar olsa da Budizm, Taoism ve Sufizm'in ayn felsefi temelden beslendiği bilinmektedir. Fark'andalık, bir kültür unsuru veya dini bir görev değil, bireylerde var olan değerlerin birikimi olarak kabul edilmektedir (Kabat-Zinn, 2003). Diğer bir deyişle fark'andalık uygulamalarının her dinde farklı şekillerde uygulandığı da görülmektedir. Budizm'de meditasyon uygulamaları, Sufizm'de tefekkür, Hinduizm'de yoga, benzer felsefeyle farklı uygulamalarda şekil bulmuştur.

Diğer yaklaşımlardan farklı olarak fark'andalık yaklaşımın bilimsel alt yapılarla açıklanıyor olması, yaklaşımı bu denli popüler kılan faktörler arasındadır. Son yıllarda hızla artan ulusal ve uluslararası araştırma bulguları fark' andalık uygulamalarının psikolojik ve somatik sorunların yanı sıra ve kişilerarası ilişkilerde de etkin olduğunu ortaya koymaktadır (Baer 2003, Brown et al. 2007). Bunun yanı sıra nöropsikolojik araştırma bulguları, uygulamaların beyni güçlendirdiği ve nöroplastisiteye katkı sunduğuna ilişkin kanıtlar sunmaktadır. Tüm bu bilgiler ışı̆̆ında, bu denli etkili olan fark'andalık uygulamaların ülkemizde de önem kazandığı görülmektedir. Bununla birlikte, başka bir kültürden alınmış uygulamaların ülkemiz kültür ve değer yapısına uyum sağlayıp sağlamayacağı soru işaretidir. Budizm temelli olduğu bilinen uygulamalarının özünde bulunan yoga ve meditasyon günümüz nesline uyum sağlasa da, binlerce yıllık süregelen kültürümüzü büyük ölçüde yansıtmadığı görülmektedir. Bu doğrultuda, başka bir kültürden beslenen yapılandırılmış bir yaklaşımın kopyalanması yerine içine doğulan kültüre uyarlanmasının daha uygun olduğu düşünülmektedir. Bu çerçevede FTSP, FTBT ve FTÖŞ gibi yapılandırılmış programların kültüre uyarlanarak uygulanması gerektiğinin önemi vurgulanmaktadır (Uzun, 2020).

\section{Sonuç ve Tartışma}

Çağın getirdiği hız modası olarak günlük yaşamında bireyler haz alma peşinde koşarken sürekli bir eylem ve aktivasyon halindedir (Uzun, 2020). İnsanlar tıpkı bir koşu bandının üzerinde koşuyormuşçasına hareket ederken kendi dünyalarına dikkatini veremez hale gelmiş ve an'ı yaşama keyfinden uzaklaşmaya başlamışlardır. 21. Yüzyılın 'becerisi' zannedilen çok yönlülük, aynı anda birden fazla işi yapabildiğimiz yanılsamasını beraberinde getirmektedir. Oysa, aynı anda birden fazla şeye odaklanma oranı, meşgul olunan eylem sayısına bölündüğünde her bir eylem için yetersiz odaklanmanın ortaya çıktı̆̆ı gerçeğini göstermektedir. Bu nedenle, son yıllarda, modern ama kaotik 
dünyanın yarattığı endişe, stres ve tükenmişlik kısır döngüsünü kırmak, olumsuz etkilerini azaltmak ve insanlardaki mutluluk ve başarı motivasyonunun yeniden kazanılmasını sağlamak üzere güncel ve tinsel bir yaklaşım oluşturulmuştur. Fark'andalık olarak tanımlanan bu yaklaşım sürekli hareket halinde olan bireylerin yapma modundan olma moduna geçebilmelerini ve an'da kalabilmelerini sağlamayı amaçlamaktadır.

Orijinal dili olan İngilizce' de de tek bir kelimeyle karşıllı̆ı bulunmayan mindfulness kavramının zengin içeriği, Türkçe karşılığının oluşmasında güçlük yaratmaktadır. Buna karşın, dilimizde kavramın anlaşılırlığını kolaylaştırmak amacıyla, içeriği büyük ölçüde karşıladığı düşünülen 'an farkındalığını' yansıtan fark' andalık kelimesi önerilmektedir. Temelini Budizm'den aldığg düşünülen yaklaşımın farklı din ve kültürlerde yüzyıllardır uygulandığı anlaşılmaktadır. Bu bağlamda seküler bir yaklaşım olarak kabul edilen fark'andalık, zihnin eğitilerek bilinçli ve yargısız biçimde içinde bulunulan an'a davet edilmesi olarak tanımlanmaktadır.

Değişen ve gelişen dünyada birçok alanda olduğu gibi ruh sağlı̆̆ı alanında da çeşitli değişimlerle kullanılan fark'andalık kavram ve uygulamalarına yer verildiği görülmektedir. Son yıllarda gelişen üçüncü dalga terapilerin temeli olan fark'andalık uygulamalarının, yetişkinlerin yanı sıra çocuklarda da iyileştirici ve geliştirici etkileri olduğu ortaya konulmuştur (Meiklejohn ve ark. 2012; Yazğan, 2019). Kaygı, öfke gibi güç duygularla baş etmede etkili olduğu görülen bu uygulamaların (Germer, 2005) eğitim alanında kullanıldığında işlevsel olacağı düşünülmekte ve buna yönelik adımlar atılmaktadır (Yıldızhan, 2018; Yazğan, 2019; Kral, 2019). Weare (2012), ruhsal ve fiziksel sağlı̆ın yanı sıra öğrenme becerilerine de katkısı nedeniyle okullara mindfulness uygulamalarına yer vermelerini önermektedir. Alan yazın çalışmaları incelendiğinde fark'andalık çalışmalarının eğitim alanında çoğunlukla Avrupa ve ABD'de de yer aldığı görülse de son yıllarda Türkiye'de de farklı örneklemlerle sınandığ1 ve bulguların uygulama yapılan gruplarda olumlu yönde değişimler gösterdiği gözlemlenmiştir. Yapılan çalışmalara dayanarak kültüre duyarlılığın artırılması ve sarmal düzende çalışmaların devam ettirilmesinin alana katkı sağlayacağı düşünülmektedir.

Yapılandırılmış içeriğinde bulunan yoga ve meditasyonun Türk kültürüne doğrudan uygulanmasının mümkün olmadığı fark edilmiş, uygulamaların doğrudan kopyalanması yerine kültüre uyarlanmasının gerekliliği vurgulanmıştır.

\section{Yazarların Makaleye Katkı Oranları}

Bilge Uzun \%50, Tennur Kral \%50

\section{Çıkar Beyanı}

Bu çalışmada yazarlar arasında çıkar çatışması bulunmamaktadır.

\section{Kaynakça}

Alidina, S. (2015). The mindful way through stress: The proven 8-week path to health, happiness, and well-being. New York: The Guilford Press.

Atalay, Z. (2011). Öz-anlayış ve Mindfulness. Ankara: Maya Akademi.

Baer, R. A. (2003). Mindfulness training as a clinical intervention: A conceptual and emprical review. Clinical Psychology: Sciense and Practice, 10(2), 125-143.

Broderick, P. C. (2005). Mindfulness and coping with dysphoric mood: Contrasts with rumination and distraction. Cognitive Therapy and Research 29(5), 501-510 Doi: 10.1007/s10608-005-3888-0

Brown, K. W., \& Ryan, R. M. (2003). The benefits of being present: Mindfulness and its role in psychological well-being. Journal of Personality and Social Psychology, 84(4), 822-848. 
Brown, K. W., Ryan, R. M. \& Creswell, J. D. (2007). Mindfulness: Theoretical foundations and evidence for its salutary effects. Psychological Inquiry 18(4), 211-237. Doi: 10.1080/10478400701598298

Cash, M., ve Whittingham, K. (2010). What facets of Mindfulness contribute to psychological well-being and depressive, anxious, and stress-related symptomatology?. Mindfulness, 1(3), 177-182.

Çakır, G., \& Uzun, B. (2018). Fark'andalık (mindfulness) ve kabul temelli terapiler. Z. Karataş ve Y. Yavuzer (Ed.), Psikolojik danışma ve psikoterapi kuramları (ss.615-652). Ankara: Pegem.

Çatak, P. D. ve Ögel, K. (2010). Mindfulness temelli terapiler ve terapötik süreçler. Klinik Psikiyatri, 13, 85-91.

Çollak, N. (2018). Okul öncesi dönem çocuklarına yönelik 8 haftalık mindfulness (bilinçli farkındalık) programı ve programın çocuklar üzerindeki etkileri, Yayımlanmamış Yüksek Lisans tezi, Bahçeşehir Üniversitesi Eğitim Bilimleri Enstitüsü, İstanbul.

Daş, C. (2012). Gestalt terapi. Ankara: HYB yayınları

Demir, V. (2014). Bilinçli farkındalık temelli hazırlanan eğitim programının bireylerin depresyon ve stres düzeyleri üzerine etkisi, Yayımlanmamış Yüksek Lisans Tezi, İstanbul Arel Üniversitesi, Sosyal Bilimler Enstitüsü, İstanbul.

Dryden, W., \& Still, A. (2006). Historical aspects of mindfulness and self-acceptance in psychotherapy. Journal of Rational-Emotive ve Cognitive-Behavior Therapy, 24(1), 3-28. doi:10.1007/s10942-006-00261.

Duncan, S. (2003). Present moment awareness. New World Library, California: Novato.

Fiorillo, D. R. \& Fruzzetti, A. E. (2015). Dialectical behavior therapy for trauma survivors. V. M. Follette, J. Briere, D. Rozelle, J. W. Hopper ve D. I. Rome (Ed.), Mindfulness oriented interventions for trauma: Integrating contemplative practices, (s. 75-90), New York: Guilford Press.

Flook, L., Smalley, S. L., Kitil, M. J., Galla, B. M., Kaiser-Greenland, S., Locke, J., Ishijima, E., \& Kasari, C. (2010). Effects of mindful awareness practices on executive functions in elementary school children. Journal of Applied School Psychology, 26(1), 70-95. Doi.org/10.1080/15377900903379125

Fulton, P. R. (2013). Mindfulness as clinical training. (Ed) C. K. Germer, R. D. Siegel, \& P. R. Fulton, Mindfulness and psychotherapy (2. ed., s. 59-75). New York: Guilford Press.

Germer, C. K. (2005). Mindfulness: What is it? What does it matter? C. K. Germer, R. D. Siegel ve P. R. Fulton (Ed.), Mindfulness and psychotherapy. New York: The Guilford Press.

Germer, C. K. (2009). The mindful path to self-compassion: Freeing yourself from destructive thoughts and emotions. New York: The Guilford Press.

Germer, C. (2013). Mindfulness: What is it? What does it matter? (Ed.) C. K. Germer, R. D. Siegel, \& P. R. Fulton, Mindfulness and psychotherapy (2. ed., s. 3-35). New York: Guilford Press.

Gilbert, P. (2005). Compassion and cruelty: A biopsychosocial approach. In P. Gilbert (Ed.), Compassion: Conceptualizations, research and use in psychoNynaponika Therapy (s. 9-74). Hove: Routledge.

Gilbert, P. (2009). Introducing compassion-focused therapy. Advances in Psychiatric Treatment, 15(3), 199208.

Ginnivan, R. (2016). Now \& Now: Transformational diaries of present moment living. Balboa Press, Bloomington.

Hanh, T. N. (1987). The miracle of mindfulness: An intruduction to the practice of meditation. Boston: Bacon Press.

Hanh, T. N. (1998). The hearth of the buddha's teaching. New York: Broadway.

Harris, R. (2016). ACT'yi kolay öğrenmek: İlkeler ve ötesi için hızlı bir başlangıç. (Kollektif çev.). İstanbul: Litera Yayıncllık.

Hayes, S. C. (2004). Acceptance and commitment therapy and the new behavior therapies: Mindfulness, acceptance, and relationship. In S. C. Hayes, V. M. Folette \& M. M. Linehan (Eds.), Minfulness and acceptance: expanding the cognitive-behavioral tradition (s. 1-29). New York: The Guilford Press.

Hayes, A.M., \& Feldman, G. (2004). Clarifying the construct of mindfulness in the context of emotion regulation and the process of change in therapy. Clinical Psychology Science and Practice, 11, 255262. 
Hayes, S. C., Strosahl, K., Bissett, K. G., Pistorello, R. T., Toarmino, D., \& Mccurry, M. A. (2004). Measuring experiential avoidance: A preliminary test of a working model. Psychological Record, 54(4), 553-578. doi.org/10.1007/BF03395492.

Hick, S. F. (2008). Cultivating therapeutic relationships: The role of Mindfulness (Edt. Hick, S. F. ve Bien, T.) Mindfulness and the therapeutic relationship. New York: The Guilford Press.

Hölzel, B. K., Lazar, S. W., Gard, T., Schuman-Olivier, Z., Vago, D. R., \& Ott, U. (2011). How does mindfulness meditation work? Proposing mechanisms of action from a conceptual and neural perspective. Perspectives on Psychological Science, 6(6), 537-559. Doi: 10.1177/1745691611419671

Janning, F. (2017). A Philosophy of Mindfulness: A Journey with Deleuze. NFB/Amelie Press.

Kabat-Zinn J. (2003) Mindfulness-based interventions in contex: Past, present and future. Clinical Psychology Science Practice, 10(2), 144-156.

Keçeli, Ş. S. (2017). Effects of Mindfulness-based skills program on psychological and metacognitive processes in generalized anxiety symptoms. Yayımlanmamış Yüksek Lisans Tezi. Bahçeşehir Üniversitesi, Sosyal Bilimler Enstitüsü, İstanbul.

Killen, J. D., Fortmann, S. P., Newman B. (2008); Extended cognitive behavior therapy for cigarette smoking cessation. Addiction, 103, 1381- 90.

Killingsworth, M. A. \& Gilbert, D. T. (2010). A wandering mind is an unhappy mind, Science, 330, 932.

Kral, T. (2019). Fark'andalık temelli psikoeğitim programının ergenlerde sınav kaygısı yönetimine etkisi. Yayımlanmamış Yüksek Lisans Tezi, Bahçeşehir Üniversitesi, Eğitim Bilimleri Enstitüsü, İstanbul.

Kumar, S. (2002). An introduction to Buddhism for the cognitive behavioral therapist. Cognitive and Behavioral Practice 9(1), 40-43. Doi: 10.1016/S1077-7229(02)80038-4

Latner, J. (1992). The theory of Gestalt therapy. E. C. Nevis (Ed.), In Gestalt therapy: Perspectives and applications (s. 13-56). Mexico: The Gestalt Institude of Cleveland.

Linehan, M.M. (2015). DBT Skills Training Manual. (2. Baskı). New York: The Guilford Press.

Mace, C. (2008). Mindfulness and mental health: Therapy, theory and science. New York: Routledge Taylor ve Francis Group.

MacKenzie, M., Abbott, K., \& Kocovski, N. (2018). Mindfulness-based cognitive therapy in patients with depression: Current perspectives. Neuropsychiatric Disease and Treatment, 14, 1599-1605.

Meiklejohn, J., Phillips, C., Freedman, M. L., Griffin, M. L., Biegel, G., Roach, A., ... \& Isberg, R. (2012). Integrating mindfulness training into K-12 education: Fostering the resilience of teachers and students. Mindfulness, 3(4), 291-307.

Mckay, M, Wood, J.C., \& Brantley, J. (2016). Diyalektik Davranışçı Terapi Beceri Öğretim Kılavuzu. (Çev. Ali And Maybek). (1. Basım). Ankara: Dev Belgesel Yapım ve Yayın.

Miller, J. J., Fletcher, K., \& Kabat-Zinn, J. (1995). Three-year follow-up and clinical implications of a Mindfulness Meditation-Based Stres Redution Intervention in the treatment of anxiety disorders. General Hospital Psychiatry, 17(3), 192-200.

Neff, K. D. (2003b). The development and validation of a scale to measure selfcompassion. Self and Identity, 2(3), 223-250.

Ögel, K. (2012). Farkındalık (Ayrımsama) ve Kabullenme Temelli Terapiler. İstanbul: HYB Yayıncllı.

Özyeşil, Z. (2011). Üniversite öğrencilerinin öz-anlayış düzeylerinin bilinçli farkındalık kişilik özellikleri ve bazı değişkenler açısından incelenmesi. Yayımlanmamış Doktora Tezi, Selçuk Üniversitesi, Eğitim Bilimleri Enstitüsü, Konya.

Palmer, A., \& Rodger, S. (2009). Mindfulness, stress, and coping among university students. Canadian Journal of Counselling, 43(3), 198.

Perry, E. C. (2017). Exploration of Mindfulness in Mindfulness-based therapy: A qualitative study. Yayımlanmamış Doktora Tezi.

Pollak, S. M, Pedulla, T., \& Siegel, R. D. (2014). Sitting together: Essential skills for mindfulness-based psychotherapy. New York: The Guilford Press.

Raes, F., \& Williams, J. M. G. (2010). The relationship between Mindfulness and uncontrollability of ruminative thinking. Mindfulness, 1(4), 199-203. 
Rinpoche, S. (2006). Tibetin yaşam ve ölüm kitabı. İstanbul: Dharma Yayınları.

Roemer, L., Orsillo, S. M., \& Salters-Pedneault, K. (2008). Efficacy of an acceptance-based behavior therapy for generalized anxiety disorder: Evaluation in a randomized controlled trial. Journal of Consulting and Clinical Psychology, 76(6), 1083.

Salmon, P. G., Santorelli, S. F., Sephton, S. E., \& Kabat-Zinn, J. (2009). Intervention elements promoting adherence to mindfulness-based stress reduction (MBSR) programs in a clinical behavioral medicine setting. In S. A. Shumaker, J. K. Ockene, \& K. A. Riekert (Eds.), The handbook of health behavior change (s. 271-286). Springer Publishing Company.

Singh, N. N., Lancioni, G. E., Winton, A. W., Karazsia, B. T., \& Singh, J. (2013). Mindfulness training for teachers changes the behavior of their preschool students. Journal Research in Human Development, 10(3), 211-233.

Shirish, J. S., Prakash, M. S., ve Shivarama, V. (2018). Effectiveness of mindfulness-based cognitive therapy in patients with bipolar affective disorder: A case series. International Journal Of Yoga, 11(1), 77-82. doi:10.4103/ijoy.IJOY_44_16

Snel, E. (2016). Bir kurbağa gibi sakin ve dikkatli. İstanbul: Pegasus Yayınları.

Smith, R. E. (1986). Toward a cognitive-affective model of athletic burnout. Journal of Sport Psychology, 8(1), 36-50. Doi: 10.1123/jsp.8.1.36

Surrey, J. L. (2005). Relational psychotherapy, relational mindfulness. In C. K. Germer, R. D. Siegel, \& P. R. Fulton (Eds.), Mindfulness and psychotherapy (s. 91-110). Guilford Press.

Orsillo, S. M., Roemer, L., \& Holowka, D. W. (2005). Acceptance-based behavioral therapies for anxiety: Using acceptance and mindfulness to enhance traditional Cognitive-Behavioral Approaches. In S. M. Orsillo \& L. Roemer (Eds.), Series in anxiety and related disorders. Acceptance and mindfulnessbased approaches to anxiety: Conceptualization and treatment (s. 3-35). Springer Science. doi.org/10.1007/0-387-25989-9_1

Teasdale, J. D., Moore, R. G., Hayhurst, H., Pope, M., Williams, S. \& Segal, Z. V. (2002). Metacognitive awareness and prevention of relapse in depression: Empirical Evidence. Journal of Consulting and Clinical Psychology, 70(2), 275-287.

Terzi, Ş. ve Tekinalp, B. (2013). Psikolojik danışmada güncel kuramlar. Ankara: Pegem Yayınları.

Thera, N. (1973). The Hearth of Buddhist Meditation. New York: Red Wheel.

Uzun, B. (2019). Mindfulness becerilerinin psikoterapide kullanımı (Çev Edt) Pollak, S. M, Pedulla, T. Siegel, R. D. (2014). Sitting together: Essential skills for mindfulness-based psychotherapy. İstanbul: Apamer Yayınları.

Uzun, B., (2020a). Farkandalık ve özgüven. Z. Kızıltepe (Ed.), Çocuklarda öz güven hakkında her şey, 4. Bölüm, Ankara: Nobel Yayınevi.

Uzun, B., (2020b). En uzun yollar tek adımla başlar. İstanbul: İnkılap Yayınevi.

Uzun, B. \& Saraç, S. (2020) Erken çocuklukta fark'andalık, namı diğer mindfulness. E. Görgü \& T. Sezer (Ed.), Erken çocuklukta güncel konular. Ankara: Nobel Yayınları.

Williams, M. ve Penman, D. (2014). Mindfulness (Çev. E. Duru). İstanbul: Pegasus Yayınları.

Yalom, I. (2001). Varoluşçu psikoterapi. (Çev. Z. İyidoğan-Babayiğit). İstanbul: Kabalcı Yayınevi.

Yazğan, Ö. (2019). İlkokul Çocuklarına Yönelik Mindful Okul Programı ve Programı Çocuklar Üzerindeki Etkileri. Yayımlanmamış Yüksek Lisans Tezi. Bahçeşehir Üniversitesi, Eğitim Bilimleri Enstitüsü, İstanbul.

Yıldızhan, Ö. (2019). Mindfulness temelli öfke yönetimi programının çocuklarda mindfulness ve öfke yönetimi becerilerine etkisi. Yayımlanmamış Yüksek Lisans Tezi. Bahçeşehir Üniversitesi, Eğitim Bilimleri Enstitüsü, İstanbul.

Watts, A. W. (1961). Psychotherapy East and West. New York: New American Library.

Zeidan, F., Johnson, S. K., Diamond, B. J., David, Z. \& Goolkasian, P. (2010). Mindfulness meditation improves cognition: Evidence of brief mental training. Consciousness and Cognition, 19(2), 597-605. 